\section{Differences in carbon isotope fractionation between angiosperm and gymnosperm woody plants, and their significance for paleoatmosphere and hydroclimate reconstruction.}

\section{VINCENT J HARE ${ }^{1,2}$ AND ALIENOR LAVERGNE ${ }^{2}$}

\author{
${ }^{1}$ University of Cape Town \\ ${ }^{2}$ Imperial College London
}

Presenting Author: vincent.john.hare@gmail.com

In terrestrial contexts, the stable carbon isotopic composition of fossil $\mathrm{C}_{3}$ plant matter is widely used as a proxy of past hydroclimate and atmospheric $\mathrm{CO}_{2}$ concentration. Presently, differences in carbon isotope discrimination $\left(\Delta^{13} \mathrm{C}\right)$ between the two major vascular plant groups, angiosperms and gymnosperms, are relatively small (2-3\%). Yet, an increasing body of evidence suggests that larger differences occurred across geological times (up to 6-7 \%). Unfortunately, an accurate first principles understanding of how different $\mathrm{C}_{3}$ plant groups respond to variable environments and atmospheres (e.g. $\mathrm{CO}_{2}$ and $\mathrm{O}_{2}$ concentrations) is currently uncertain, with important consequences for the interpretation of the fossil record, and the accuracy of paleo-proxies.

Here we develop a comprehensive $a b$ initio model of discrimination, to show how differences in $\Delta{ }^{13} \mathrm{C}$ between angiosperms and gymnosperms arise from three key physiological differences: (1) the ratio of cost factors for transpiration to carboxylation (higher in angiosperms); (2) the ratio of mesophyll to stomatal conductance of $\mathrm{CO}_{2}$ (lower in gymnosperms); and (3) differences in photorespiration. As a result of these factors, angiosperm $\Delta^{13} \mathrm{C}$ is more sensitive to $\mathrm{CO}_{2}$, and gymnosperm $\Delta^{13} \mathrm{C}$ is more sensitive to VPD. Isotopic data from $20^{\text {th }}$ century leaves, tree rings $(n>7000)$ and previouslypublished plant chamber experiments, along with geological data from the Cenozoic, agree with our model over a range of $\mathrm{O}_{2}: \mathrm{CO}_{2}$ ratios from 100 to $650 \mathrm{~mol} \mathrm{~mol}^{-1}$ (equivalent to a $\mathrm{CO}_{2}$ range of around $323-2000 \mathrm{ppm}$ at $21 \% \mathrm{O}_{2}$ ), and VPD levels between 0.45 and $1.1 \mathrm{kPa}$.

Our new framework offers a refined explanation for secular trends in $\Delta^{13} \mathrm{C}$ in the geological record, and reconciles previously unexplained observations, such as covariation of modern tree ring $\Delta_{\text {a-g }}^{*}$ with latitude (and VPD), variable $\mathrm{O}_{2}$, and differences during glacial maxima. We show how incorporating differences in plant responses can improve estimates of past hydroclimate and atmospheres, by applying the new framework to the MidMiocene Climatic Optimum (MMCO, 17 to $15 \mathrm{Ma}$ ago). We find a likely range of $\mathrm{CO}_{2}$ between 550 and $700 \mathrm{ppm}$, at VPD levels between 0.8 and $1.4 \mathrm{kPa}$, in broad agreement with other paleo$\mathrm{CO}_{2}$ proxies from phytane, and $\delta^{11} \mathrm{~B}$.
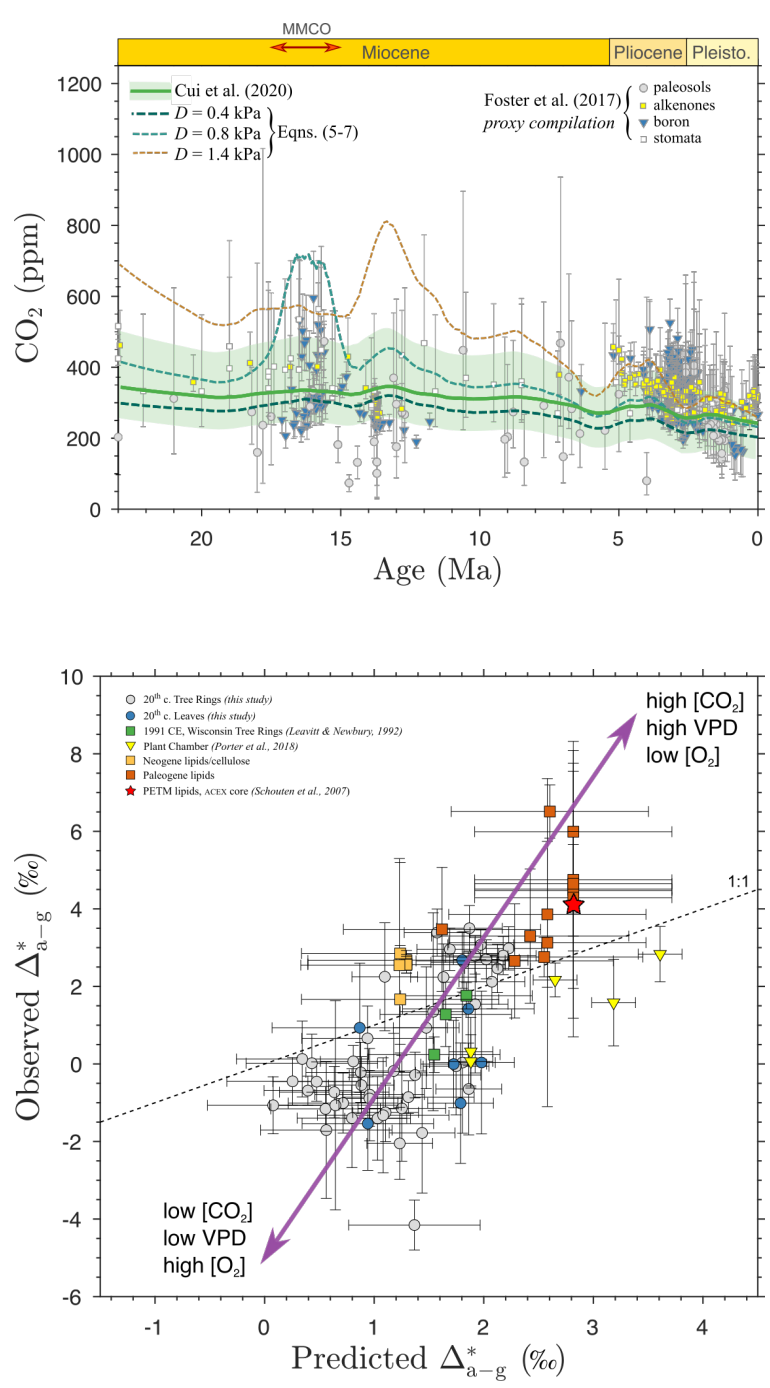